\title{
Observational Histopathological Analysis of Renal Lesions in Nephrectomy Specimens
}

\author{
Anita Kumari ${ }^{1}$, Sarmistha Subhadarsini ${ }^{2}$, U S Pandey ${ }^{3}$ \\ ${ }^{1}$ Tutor G.M.C Bettiah, Bihar, India. \\ ${ }^{2}$ Senior Resident, Department of Pathology, Saheed Laxman Nayak Medical College \& Hospital, Koraput, \\ Odisha, India. \\ ${ }^{3}$ HOD, Department of Pathology GMC Bettiah, Bihar, India
}

Corresponding Author: Sarmistha Subhadarsini

\begin{abstract}
Aim: This observational retrospective study was initiated to perform histopathological spectrum analysis of renal lesions from resected nephrectomy specimens.

Materials and Methods: This was a retrospective observational study. Over a span of 4 years a total of 62 nephrectomy cases who underwent nephrectomy in a tertiary health care center and specimens were received from the surgical Department of the Hospital were analysed. Microscopic and gross features of the specimen were studied.
\end{abstract}

Result: 12(19\%) nephrectomy specimens out of 62 were malignant and $50(81 \%)$ were benign. The mean age of patients from whom specimen were collected was $44.16 \pm 29.8$ years. 34 (54.9\%) were Chronic Pyelonephritis cases, some associated with hydronephrosis and others with calculi. Out of 12 total malignant lesions 8 cases $(12.9 \%)$ constituted as renal cell carcinoma. Among children commonest malignant tumour was Wilm's tumour. Among the clinical presentation most common was flank pain in $17(53.1 \%)$ cases followed by fever and burning micturition.

Conclusion: In current study as compared to the benign tumours, malignant renal tumours far outnumbered. In paediatric age group most common malignancy was the Wilms tumour. Most common histomorphological diagnosis was Chronic Pyelonephritis and among the malignant lesions commonest were Renal Cell Carcinoma.
Keywords: Nephrectomy, Histopathology, Chronic Pyelonephritis, Wilm's tumour, Renal Cell Carcinoma

\section{INTRODUCTION}

Renal disease is considered to be having very high number of morbidity and appears very complex in nature ${ }^{[1]}$. Apart of maintenance of salt and water metabolism kidney's also perform additional vital functions like acid base balance and excretory function. For both malignant and benign lesions of the kidney, nephrectomy is done. It has been generally observed that irreversible kidney damage were found in benign category resulting from severe traumatic injury, calculi or infections. Whereas Wilm's tumour and Renal Cell Carcinoma are commonest in the malignant category. In generally for Renal Cell Carcinoma treatment of choice is the nephrectomy ${ }^{[2]}$.

As per the epidemiological recent data $3.3 \%$ of all newly diagnosed cancer was renal cancer which is also 7 th most common malignancy ${ }^{[3]}$. As documented by H. Moch et al, globally 16th most common cause of death is renal cancer ${ }^{[4]}$. As per the recent data, in worldwide 13th most common malignancy is Renal Cell Carcinoma (RCC) ${ }^{[5]}$. With few rare tumours in both adults and in children wide spectrum of entities of renal neoplasms generally found. Different components of the renal parenchyma, which includes 
interstitial tissue, renal tissue, tubular epithelium etc., can generate renal neoplasms from primitive elements ${ }^{[6]}$.

Both malignant and Benin tumors where founds in pediatric which itself is uncommon in nature. In children most common renal malignancy is Wilms tumor (nephroblastoma). Apart of this other type of renal tumors found in pediatric are commonly mesoblastic nephroma, metanephric adenoma, lymphoma multilocular cystic renal tumor, angiomyolipoma, rhabdoid tumor etc.

This observational retrospective study was initiated to perform histopathological spectrum analysis of renal lesions from resected nephrectomy specimens.

\section{MATERIALS AND METHODS}

This was a retrospective observational study. Over a span of 4 years a total of 62 nephrectomy cases who underwent nephrectomy in a tertiary health care center and specimens were received from the surgical Department of the Hospital were analysed. Microscopic and gross features of the specimen were studied.

A predesigned pro forma were used to capture demographic and other details. The details to perform the study were generally extracted from the patients' clinical records. From the archives paraffin blocks and histopathology slides were retrieved for all participants. As per CAP guidelines 2017 histopathological parameters were assessed. Tumour stage was assessed as per Fuhrman nuclear grade and WHO classification 2016. Inform consent were obtained from each patients.

All data were presented in Microsoft excel and statistical calculation was done by using statistical software (Social Sciences version 20, SPSS Inc. Chicago, IL, USA).

\section{RESULT}

$12(19 \%)$ nephrectomy specimens Out of 62 were malignant and $50(81 \%)$ were benign (Table 1).

Table No.1: Distribution of Benign and Malignant lesions

\begin{tabular}{|l|l|}
\hline Lesions & No. of Cases (\%) \\
\hline Benign & $44(81 \%)$ \\
\hline Malignant & $12(19 \%)$ \\
\hline
\end{tabular}

$4(33 \%)$ were female and $8(67 \%)$ of patients were male out of the 12 cases of malignancies with male: female ratio of $2: 1$.

The mean age of patients from whom specimen were collected was $44.16 \pm$ 29.8 years. In age group of 41-60 years 5160 years maximum number of cases were found (Table 1) (Figure 1).

Table No.2: Age-wise Nephrectomy specimens

\begin{tabular}{|l|l|}
\hline \multicolumn{2}{|c|}{ Table No.2: Age-wise Nephrectomy specimens } \\
\hline O-20 & No. of Cases (\%) (N=62) \\
\hline $21-40$ & $9(14.5 \%)$ \\
\hline $41-60$ & $17(27.4 \%)$ \\
\hline$>60$ & $26(41.9 \%)$ \\
\hline
\end{tabular}

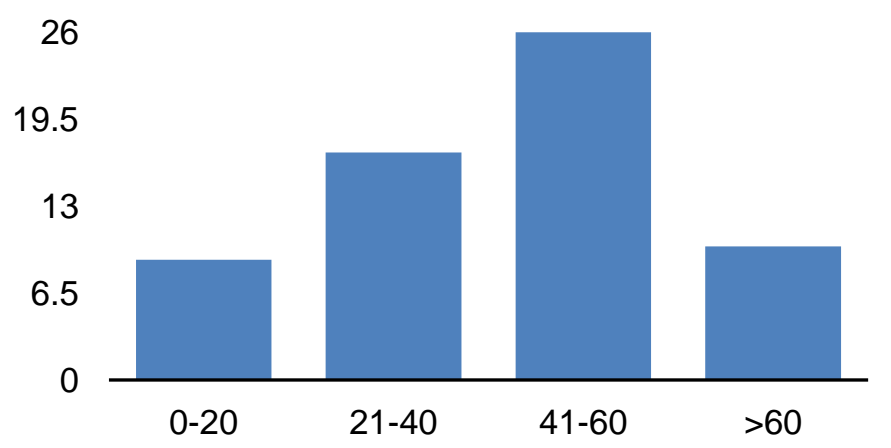

Figure 1: Depicting the distribution of renal tumours among different age groups 
$34 \quad(54.9 \%) \quad$ were Chronic Pyelonephritis cases, some associated with hydronephrosis and others with calculi. Out of 12 total malignant lesions 8 cases $(12.9 \%)$ constituted as renal cell carcinoma. Among children commonest malignant tumour was Wilm's tumour.

Table No.3: Distribution of Nephrectomy specimens according to Histopathological lesions

\begin{tabular}{|l|l|}
\hline Lesions & No. of Cases (\%) \\
\hline CPN & $34(54.9 \%)$ \\
\hline Xanthogranulomatous Pyelonephritis & $3(4.8 \%$ \\
\hline Pyonephrosis & $1(1.6 \%)$ \\
\hline Polycystic Kidney Disease & $5(8 \%)$ \\
\hline Traumatic Kidney & $4(6.5 \%)$ \\
\hline Hydatid Cyst Kidney & $1(1.6 \%)$ \\
\hline Renal Cell Carcinoma & $8(12.9 \%)$ \\
\hline Renal Sarcoma & $1(1.6 \%)$ \\
\hline Wilm's Tumour & $3(4.8 \%$ \\
\hline Oncocytoma & $1(1.6 \%)$ \\
\hline TCC of Ureter & $1(1.6 \%)$ \\
\hline
\end{tabular}

Among the clinical presentation most common was flank pain in $45(72,5 \%)$ cases followed by fever and burning micturition.

Table No.5: Clinical Presentation in patients undergoing Nephrectomy

\begin{tabular}{|l|l|}
\hline Clinical Features & No. of Cases (\%) $(\mathbf{N}=62)$ \\
\hline Hematuria & 10 \\
\hline Flank pain & 45 \\
\hline Fever & 40 \\
\hline Burning Micturition & 34 \\
\hline Lump Abdomen & 12 \\
\hline
\end{tabular}

\section{DISCUSSION}

In our study it has been observed that $12(19 \%)$ nephrectomy specimens Out of 62 were malignant and $50(81 \%)$ were benign. Thus in current study as compare to the benign tumours, malignant renal tumours far outnumbered. Rafique $\mathrm{M}$ et al ${ }^{[7]}$, Aiman A et al ${ }^{[2]}$ and Gupta A et al ${ }^{[8]}$ had already documented similar kind of observation in their previous studies. Badmus TA et al ${ }^{[9]}$ and Lathif $F$ et al ${ }^{[10]}$ also reported earlier the similar male female ration as the author observed in the current studies.

The mean age of patients from whom specimen were collected was $44.16 \pm$ 29.8 years. In age group of 41-60 years $51-$ 60 years maximum number of cases were found. Kathirvelu $S$ et al ${ }^{[11]}$ are also documented similar observation in their earlier study where they also found in the age group of 51-60 years maximum cases were seen.

$$
\text { In current retrospective }
$$
observational study it was observed that 34 (54.9\%) were Chronic Pyelonephritis cases, some associated with hydronephrosis and others with calculi. Out of 12 total malignant lesions 8 cases (12.9\%) constituted as renal cell carcinoma. Thaker $\mathrm{BD}$ et al ${ }^{[12]}$ and Popat $\mathrm{VC}$ et al ${ }^{[13]}$ were also documented in their study that Chronic Pyelonephritis was the most common indication for nephrectomy.

Renal Cell Carcinoma was the majority of malignant neoplasms of Kidney as documented in this study. Similar observation was also documented in several previous studies conducted at a tertiary care hospital in India ${ }^{[7,14]}$.

$28 \%$ cases upper pole was the location of the tumour, followed by lower pole in $25 \%$ cases and on either sides distribution of renal tumors were equal. In an earlier study, Amin AN et al. [15], reported left sided in $46.9 \%$ cases and $53.1 \%$ on right sides where as $46.1 \%$ in right side and $53.8 \%$ in left side were reported by Bashir $\mathrm{N}$ et al ${ }^{[16]}$.

With an equal gender incidence in this study Wilms tumor was the major childhood neoplasm as observed in this study. Similar observation also reported in earlier studies ${ }^{[17]}$.

\section{CONCLUSION}

In current study as compare to the benign tumours, malignant renal tumours far outnumbered. In paediatric age group most common malignancy was the Wilms tumour. Most common histomorphological diagnosis was Chronic Pyelonephritis and among the malignant lesions commonest were Renal Cell Carcinoma.

\section{Acknowledgement: None}

\section{Conflict of Interest: None}

\section{Source of Funding: None}




\section{Ethical Approval: Approved}

\section{REFERENCES}

1. Kumar V, K.A, Fausto N. Robbins and Cotran Pathologic Basis of Disease: 2005; 7: 956-962.

2. Aiman A, Singh K, Yasir M. Histopathological spectrum of lesions in nephrectomy specimens: A five-year experience in a tertiary care hospital. J Sci Soc 2013;40:148-54.

3. Ferlay, J., Soerjomataram, I., Ervik, M. et al. GLOBOCAN 2012v1.0, Cancer Incidence and Mortality Worldwide. IARC Cancer Base No. 11. Lyon, France: International Agency for Research on Cancer. 2013

4. H. Moch, Amin M.B, Argani P, Cheville J, Delahunt B, Martignoni G.et al. World Health Organization Classification of Tumours of the Urinary System and Male Genital Organs. Lyon: IARC Press; 2016, p.14.

5. Ray R, Mahapatra R, Khullar S, Pal D, Kundu A. Clinical characteristics of renal cell carcinoma: Five years review from a tertiary hospital in Eastern India. Indian J Cancer. 2016;53(1):114-17.

6. Datta B, Giri A, Halder B. Histopathological evaluation of surgically treated adult renal tumours. report from a Tertiary Care Centre in India. India $\mathbf{J}$ Cancer. 2016;53:124-26.

7. Rafique M. Nephrectomy: Indications, complications and mortality in 154 consecutive patients. J Pak Med Assoc 2007; 5: 35-8.

8. Gupta A, Bhardwaj A. Histopathological spectrum of lesions in Nephrectomy specimens in a tertiary care hospital in North India. Volume 08 Issue 02 February 2020.

9. Badmus TA, Salako AA, Sansui AA et al. Adult nephrectomy: our experience at llelfe. Niger J Clin Pract 2008; 11(2): 121-6.
10. Lathif F, Mubarak M, Kazi JI. Histopathological characteristics of adult renal tumours: a preliminary report. J Pak Med Assoc 2011; 61: 224-8.

11. Kathirvelu S, Rajvaithy A, KV, Kotasthane D. Histopathological spectrum of Nephrectomy specimen in a tertiary care centre: with an emphasis on Chronic Pyelonephritis. Annals of Pathology and Laboratory Medicine. 2017; 4(5): 573-578.

12. Thaker BD, Singh K.A Histopathological Review of Nephrectomy Specimens Received in a Tertiary Care Hospital-A Retrospective Study. Journal of Medical Science And clinical Research. 2017; 05(06): 23807-23810.

13. Popat VC, Kumar MP, Udani D, Mundra MP, Vora DN, Porecha MM. A Study On Culprit Factors, Ultimately Demanding Nephrectomy. The Internet Journal of Urology. 2009; 7(1): 1-8.

14. Shaila, Nityananda B.S, Tamil Arasi. Spectrum of lesions in Nephrectomy Specimens in a Tertiary care Hospital. J Evo Med Den Sci. 2015; 4(73): 12714- 12726.

15. Amin AN, Pai P, Upadhyaya K. A Histopathological spectrum of nephrectomy specimens in a tertiary care hospital in Southern India. Int $\mathbf{J}$ Biol Med Res. 2015;6(3):5173-78.

16. Bashir N, Bashir Y, Shah P, Bhat N, Salim O, Samoon N et.al. Histopathological study of renal tumours in resected nephrectomy specimens - an experience from tertiary care centre. Nat J Med Res. 2015;5(1):2529.

17. Mohan BP, Krishnan SK, Deepa S, Pothen L. Pattern of Renal Tumors: A Tertiary Care Center Experience over a decade. JMSCR Volume 06 Issue 02 February 2018.

How to cite this article: Kumari A, Subhadarsini S, Pandey US. Observational histopathological analysis of renal lesions in nephrectomy specimens. International Journal of Research and Review. 2021; 8(4): 18-21. DOI: https://doi.org/10.52403/ijrr.20210403 